\title{
Estimating Drag and Heat Transfer Coefficient of a Runner by Using Numerical Methods
}

Gholamhossein Lari*1 and Alireza Tahavvor ${ }^{2}$

${ }^{1}$ Safety and Fire Fighting Organization, Shiraz Municipality, Shiraz, Iran

${ }^{2}$ Department of Mechanical Engineering, Shiraz Azad University, Shiraz, Iran

\begin{abstract}
In this project, the drag coefficient of a runner and its heat transfer coefficient is calculated by modeling the runner and its networking in the Gambit and then analyzing and solving fluid flow around the model in the Fluent. The coefficient or coefficients are compared with the previous values obtained and the accuracy of the method performed in the calculation is determined. The above coefficients are calculated for six different velocities, and finally, a correlation is obtained for the coefficient of heat transfer of the runner and the numerical value for its drag coefficient.
\end{abstract}

Keywords: Runner; Drag coefficient; Heat transfer coefficient

\section{List of Symbols}

C: Special heat $\mathrm{J} / \mathrm{kg}^{\circ} \mathrm{C}$

$\mathrm{k}$ : Coefficient of conduction heating, $\mathrm{W} / \mathrm{m}^{\circ} \mathrm{C}$

$\overline{N u}$ : Average Nusselt number

p: Pressure

Re: Reynolds number

T: Temperature

$\mathrm{u}$ : Speed in line $\mathrm{x}$

$\mathrm{v}$ : Speed in line $\mathrm{y}$

w: Speed in line $\mathrm{z}$

\section{Greek signs}

$\rho:$ Density $\mathrm{kg} / \mathrm{m}^{3}$;

$\mu$ : Viscosity coefficient, $\mathrm{kg} / \mathrm{m}-\mathrm{s}$

\section{Introduction}

Each runner in the air is under the influence of the air resistance but how much is the air resistance that we would like to reduce it? The air resistance is negligible, but it's probably so small that it produced a hundredth of a second. By changing the runner's clothing, or by reducing the drag coefficient, which is the subject of the first part of the work, the effect of reducing the resistance of the air can be reduced.

In the second section, the calculation of the heat transfer coefficient is main aim. In this section, the discussion will be slightly different. As the air has a bit of resistance to the runner's motion, but heat forms a major part of the energy dissipation of the body.

According to the recent studies, information about drag coefficient of runner is a little. So by comparison the results are confirmed by other scenarios in the sources and based on these states, along with the particular state that is the runner, the accuracy of the results is confirmed. At the end of this section with respect to the results, heat transfer coefficient will be calculated [1,2].

\section{Governing Equations}

The governing equations in the three-dimensional flow state, the incompressible flow, the smooth flow (Laminar) and solid state (Steady) Include:

Continuity equation [1]:

$\frac{\partial u}{\partial x}+\frac{\partial v}{\partial y}+\frac{\partial w}{\partial z}=0$

Momentum equation [1]:

$$
\begin{aligned}
& \rho\left(\grave{u} \frac{\partial u}{\partial x}+v \frac{\partial u}{\partial y}+w \frac{\partial u}{\partial z}\right)=-\frac{\partial p}{\partial x}+\left(\frac{\partial^{2} u}{\partial x^{2}}+\frac{\partial^{2} u}{\partial y^{2}}+\frac{\partial^{2} u}{\partial z^{2}}\right) \\
& \rho\left(\grave{u} \frac{\partial v}{\partial x}+v \frac{\partial v}{\partial y}+w \frac{\partial v}{\partial z}\right)=-\frac{\partial p}{\partial y}+\left(\frac{\partial^{2} v}{\partial x^{2}}+\frac{\partial^{2} v}{\partial y^{2}}+\frac{\partial^{2} v}{\partial z^{2}}\right) \\
& \rho\left(\grave{u} \frac{\partial w}{\partial x}+v \frac{\partial w}{\partial y}+w \frac{\partial w}{\partial z}\right)=-\frac{\partial p}{\partial z}+\left(\frac{\partial^{2} w}{\partial x^{2}}+\frac{\partial^{2} w}{\partial y^{2}}+\frac{\partial^{2} w}{\partial z^{2}}\right)
\end{aligned}
$$

Energy equation [2]:

$$
\rho C\left(u \frac{\partial T}{\partial x}+v \frac{\partial T}{\partial y}+w \frac{\partial T}{\partial z}\right)=k\left(\frac{\partial^{2} T}{\partial x^{2}}+\frac{\partial^{2} T}{\partial y^{2}}+\frac{\partial^{2} T}{\partial z^{2}}\right)
$$

\section{Numerical Solution}

The final model is shown in Figure 1. In Table 1 the dimensions of the final model are specified. Figure 2 also shows the computational field and Table 2 describes the field dimensions.

Since the problem is solved by using a finite volume method, it should create the appropriate elements in it. The grid used here is non-structured model (Unstructured). Elements are of the same type TGrid and Tet/Hybrid have been selected. The network has 331,016 nodes. This network has been selected after several studies to obtain an independent response to the network.

*Corresponding author: Gholamhossein Lari, Safety and Fire Fighting Organization, Shiraz Municipality, Shiraz, Iran, Tel: +98 353123 2222; E-mail: gh.lari@gmail.com

Received December 01, 2017; Accepted January 08, 2018; Published January 18, 2018

Citation: Lari G, Tahavvor A (2018) Estimating Drag and Heat Transfer Coefficient of a Runner by Using Numerical Methods. Fluid Mech Open Acc 5: 183. doi: 10.4172/2476-2296.1000183

Copyright: $\odot 2018$ Lari G, et al. This is an open-access article distributed unde the terms of the Creative Commons Attribution License, which permits unrestricted use, distribution, and reproduction in any medium, provided the original author and source are credited. 
Citation: Lari G, Tahavvor A (2018) Estimating Drag and Heat Transfer Coefficient of a Runner by Using Numerical Methods. Fluid Mech Open Acc 5: 183. doi: 10.4172/2476-2296.1000183

Page 2 of 3
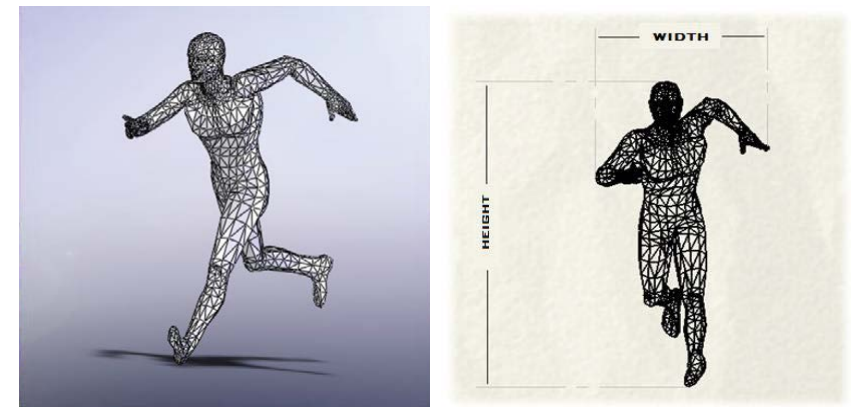

Figure 1: Geometric model.
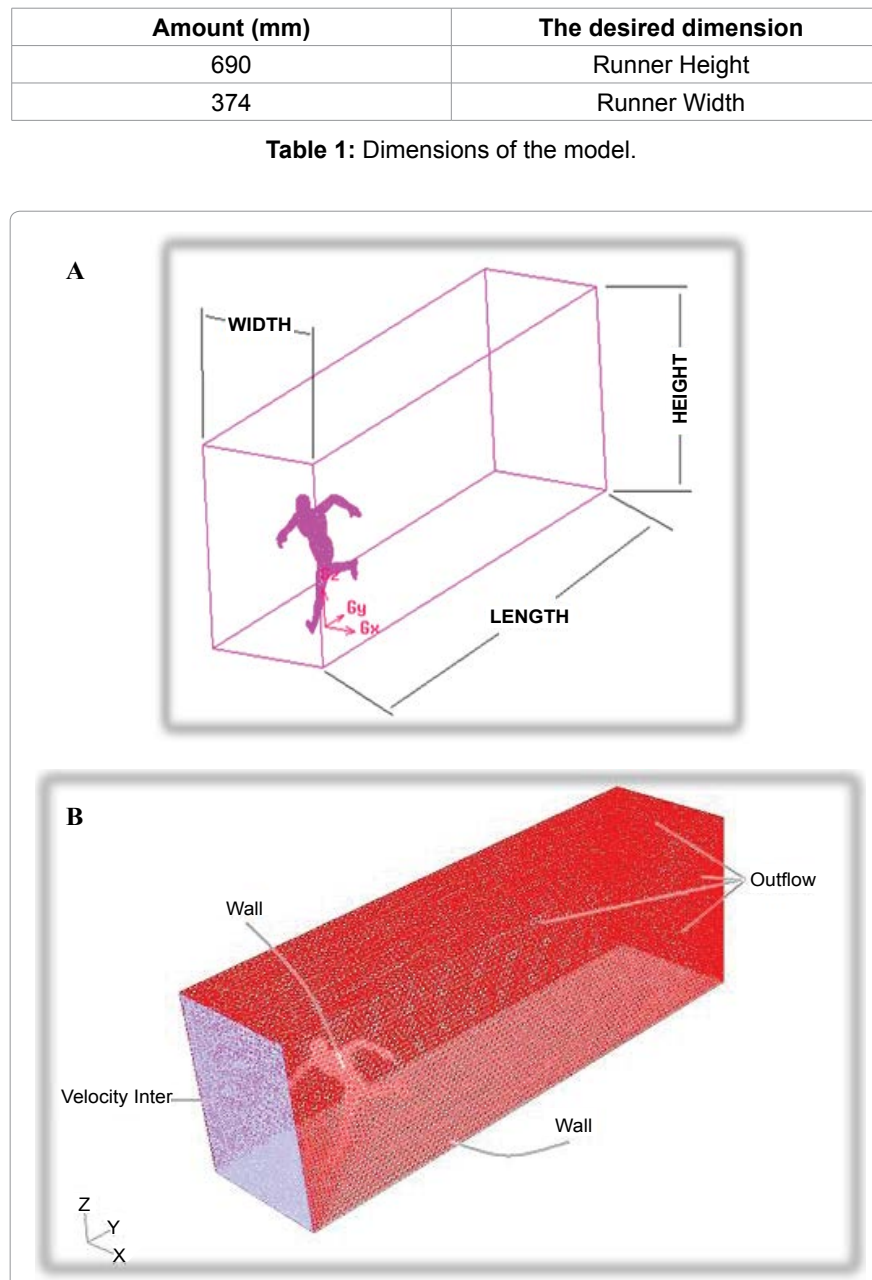

Figure 2: $(A$ and $B)$ Computational field.

Undoubtedly one of the most important parts of the problem is the correct selection of boundary conditions. In the present work as shown in Figure 2B. The input border is Velocity Inlet, The lower boundary is Wall and other boundaries are Outflow. Runner is Wall too. Values of boundary conditions are given in Table 3 . The speed of the entry is the average speed of several runners.

The surface temperature of the skin of the runner is $35^{\circ} \mathrm{C}$. The reason for this choice is shown in Figure 3 [3]. This diagram shows the changes in skin surface temperature in terms of the temperature of the environment. Referring to Figure 3, the surface temperature of the skin, while the ambient temperature is $25^{\circ} \mathrm{C}$ is equal to $32^{\circ} \mathrm{C}$. But the body's deep temperature is roughly 3 degrees higher than normal.

Using a 3D model with a regular accuracy, segregated model and laminar flow, problem will be solved. The reference values used to calculate the coefficients are also specified in Table 4.

Convergence criterion of equations is $10^{-3}$ but it needs to be explained that the criterion for obtaining a constant solution, is constant value of the drag coefficient, which happens with the transition from the above value.

\section{Results}

The values of the drag coefficient found in different resources for various activities are shown in Table 5 [4].

After solving the problem in 9 different networks and when it changes to independent of network, the drag coefficients and heat

\begin{tabular}{|c|c|}
\hline Amount $(\mathbf{m m})$ & The desired dimension \\
\hline 3000 & Length \\
\hline 750 & Width \\
\hline 1050 & Height \\
\hline
\end{tabular}

Table 2: Dimensions of the computational field.

\begin{tabular}{|c|c|}
\hline Amount & Border \\
\hline $8(\mathrm{~m} / \mathrm{s})$ & Runner Speed (or Air Intake Speed) \\
\hline $25(\mathrm{C})$ & Air temperature \\
\hline $35(\mathrm{C})$ & Body temperature of runners \\
\hline
\end{tabular}

Table 3: Boundary conditions.

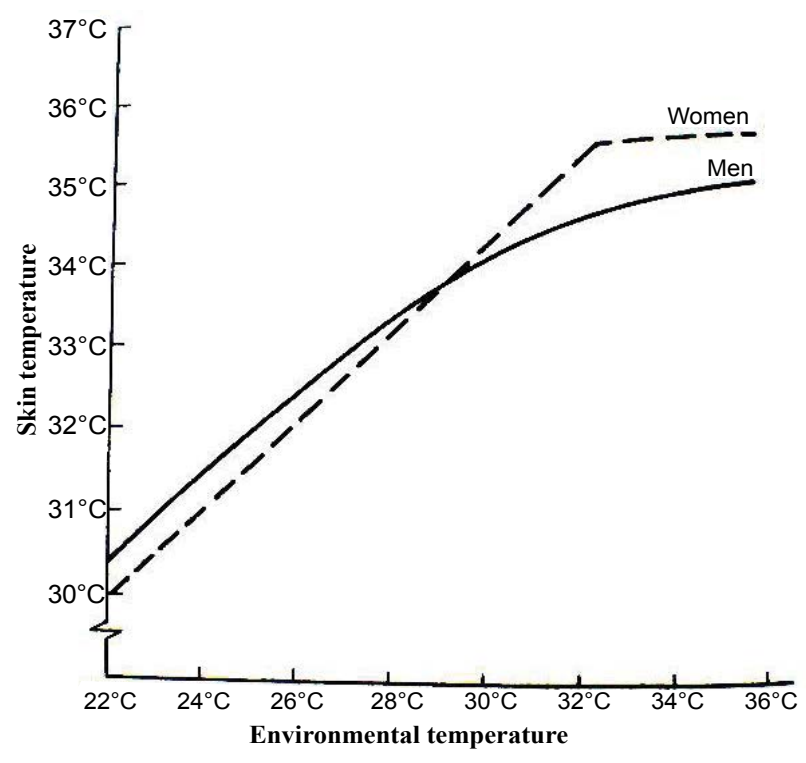

Figure 3: Changes in surface temperature of the skin in terms of the temperature of the environment.

\begin{tabular}{|c|c|}
\hline Amount & Variable \\
\hline $0.09309376\left(\mathrm{~m}^{2}\right)$ & Area of the image \\
\hline $1.225\left(\mathrm{~kg} / \mathrm{m}^{3}\right)$ & Fluid density \\
\hline $700(\mathrm{~mm})$ & Characteristic length \\
\hline $30(\mathrm{C})$ & Temperature \\
\hline $0.0000178(\mathrm{~kg} / \mathrm{m}-\mathrm{s})$ & Viscosity coefficient \\
\hline
\end{tabular}

Table 4: Reference values. 
Citation: Lari G, Tahavvor A (2018) Estimating Drag and Heat Transfer Coefficient of a Runner by Using Numerical Methods. Fluid Mech Open Acc 5: 183. doi: 10.4172/2476-2296.1000183

Page 3 of 3

\begin{tabular}{|c|c|}
\hline Drag coefficient & Activity type \\
\hline $1-1.3$ & Man (standing position) \\
\hline $1.2-1.3$ & Skier jump \\
\hline $1-1.1$ & Skier \\
\hline $1-1.4$ & Parachute \\
\hline 0.9 & Bike ride with bike \\
\hline 1.1 & Cyclist 1 \\
\hline 0.88 & Cyclist 2 \\
\hline $1-1.3$ & Skier jump \\
\hline
\end{tabular}

Table 5: Drag coefficients for several human activities.

\begin{tabular}{|c|c|}
\hline Drag coefficient & Speed $\mathbf{( m / s )}$ \\
\hline 0.693 & 6 \\
\hline 0.692 & 7 \\
\hline 0.691 & 8 \\
\hline 0.691 & 9 \\
\hline 0.691 & 10 \\
\hline 0.69 & 11 \\
\hline 0.88 & Cyclist 2 \\
\hline $1-1.3$ & Skier jump \\
\hline
\end{tabular}

Table 6: Drag coefficient values at different speeds.

\begin{tabular}{|c|c|c|}
\hline Nusselt number & Reynolds number & Speed (m/s) \\
\hline 1312.262 & 289000 & 6 \\
\hline 1328.523 & 337000 & 7 \\
\hline 1341.486 & 385000 & 8 \\
\hline 1352.057 & 434000 & 9 \\
\hline 1360.36 & 482000 & 10 \\
\hline 1367.671 & 530000 & 11 \\
\hline 0.88 & Cyclist 2 & \\
\hline $1-1.3$ & Skier jump & \\
\hline
\end{tabular}

Table 7: Heat transfer coefficient at different speeds. transfer coefficients are obtained for six different speeds, as shown in Tables 6 and 7.

\section{Conclusions}

Regarding to Table 7, the drag coefficient can be set to a constant value of 0.69 which is reasonable and acceptable in comparison with the drag coefficients for other activities. Also, using power regression, we can determine the relation for Nusselt number in terms of Reynolds number as follows:

$$
\overline{N u}=555.1 R e^{0.0685} .
$$

\section{References}

1. Shames I (2003) Mechanics of Fluids (4thedn) McGraw-Hill, USA.

2. Frank P, Incropera, Dewitt DP (2002) Introduction to Heat Transfer (4thedn), John Wiley \& Sons.

3. Leo J, Bakhtiari A (2002) Electrotherapy, Secondary principles and application of therapeutic energy, Tehran - Bakhtiari.

4. Hoerner SF (1965) Fluid Dynamic Drag, Hoerner Fluid Dynamics, USA 